\title{
PENGEMBANGAN EDUCATION GAME (EDUGAME) BERBASIS ANDROID PADA MATA PELAJARAN BAHASA INGGRIS UNTUK PESERTA DIDIK SEKOLAH DASAR
}

\author{
Wanda Ramansyah \\ Universitas Trunojoyo Madura \\ Bangkalan, --------., Indonesia \\ wandaramansyah@hotmail.com
}

\begin{abstract}
ABSTRAK
Mata pelajaran Bahasa Inggris dengan tema "My Body" adalah mata pelajaran yang mengajarkan peserta didik tentang anggota badan dalam Bahasa Inggris, baik cara penulisan maupun cara membacanya. Permasalahan muncul karena belajar menggunakan buku dirasa kurang maksimal karena buku hanya menyajikan tulisan dan gambar anggota badan tanpa menampilkan suara cara membacanya dalam Bahasa Inggris. Education game akan menyelesaikan permasalahan ini dengan menampilkan permainan serta visualisasi animasi bagian-bagian anggota badan diserta audio cara membacanya dalam Bahasa Inggris. Dengan adanya education game ini maka peserta didik akan lebih mudah dan cepat memahami materi pelajaran, selain itu proses pembelajaran akan lebih menghibur dan menyenangkan.
\end{abstract}

Kata Kunci: education, game, Bahasa Inggris

\begin{abstract}
English courses with the theme "My Body" is a subject that teaches students about the parts of the body in English, both how to write and how to read it. Problems arise because learning to use the book feels less than the maximum because the book presents only text and images the parts of the body without displaying sound how to read in English. Education games will solve this problem by displaying the game as well as animated visualization about the parts of the body accompanied audio how to read in English. Using the education game, the students will be more easily and quickly understand the subject matter, in addition to the learning process will be more entertaining and enjoyable.
\end{abstract}

Keywords: education, game, English 


\section{Pendahuluan}

Salah satu komponen penting pembelajaran. Media pembelajaran tidak dapat dipisahkan dari proses pembelajaran karena media pembelajaran berperan penting dalam menyalurkan pesan dan informasi dari sumber belajar kepada siswa. Tanpa adanya saluran atau media pembelajaran maka info yang akan disampaikan kepada siswa tidak dapat tersampaikan dengan maksimal, atau bahkan lebih berbahaya akan disalahartikan saat diserap siswa.

Dalam hasil studinya, Rudi Susilana (2007) menyampaikan bahwa keberadaan media belajar di sekolah masih memprihatinkan dan masih memerlukan pengembangan, baik jenis atau ragam dan kuantitasnya sesuai dengan tuntutan implementasi kurikulum. Media belajar juga masih terbatas hanya berupa buku dan laboratorium saja. Hal tersebut tentu saja dirasakan masih kurang melihat jaman yang semakin maju dan perkembangan teknologi yang semakin pesat. Perlu adanya inovasi dalam dunia pendidikan agar pembelajaran dapat bermakna dan mengikuti perkembangan jaman.

Jaman yang berkembang ditandai dengan teknologi yang semakin mutakhir. Sudah tidak bisa dipungkiri bahwa masa kini adalah masa yang serba digital. Kehidupan sehari-hari manusia jaman sekarang tidak bisa lepas dari teknologi, dari yang tua sampai yang muda menggunakan teknologi. Hal ini berimbas juga pada gaya hidup atau tradisi manusia. Bisa kita lihat jaman sekarang bahwa anakanak tidak lagi memainkan permainanpermainan tradisional seperti: petak umpet, patil lele, gobak sodor, lompat tali, dakon, dan lain sebagainya. Hal ini disayangkan karena permainan tradisional tersebut mengajarkan banyak hal positif seperti: kerjasama, kejujuran, kerja keras, kesabaran, dan lain-lain.
Anak-anak jaman sekarang lebih cenderung memainkan video game atau permainan yang bersifat digital dan virtual melalui console, seperti: android, tablet, komputer, playstation, xbox, nintendo, gameboy, PSP, dan sebagainya. Terkadang mereka tidak sadar bahwa permainan yang mereka mainkan tersebut mengandung nilai-nilai negatif, seperti: kekerasan, pornografi, individualisme, hanya mengandung unsur hiburan semata, dan tidak mengandung unsur edukasional. Namun faktanya sulit untuk mencegah anak-anak untuk tidak memainkan game yang penyebarannya sudah merajalela tersebut. Fakta tersebut masuk akal karena game-game digital yang beredar di pasaran mampu menyajikan keseruan, keasikan, dan tantangan yang memang sesuai dan diinginkan oleh anak-anak.

Aplikasi game untuk media pembelajaran atau disebut juga education game yangbermula dari perkembangan video game yang sangat pesat dapat menjadikannya sebagai media alternatif untuk kegiatan pembelajaran. Pembantu Rektor III ITS, Suasmoro mengungkapkan game edukasi ini perlu dikembangkan dan seharusnya game tidak hanya menyenangkan tapi juga dapat mendidik (republika.co.id, 2011). Melihat kepopuleran game tersebut, para pendidik berpikir bahwa mereka mempunyai kesempatan yang baik untuk menggunakan komponen rancangan game dan menerapkannya pada pembelajaran yang disesuaikan dengan kurikulum. Di mana game yang dirancnag untuk pembelajaran harus memiliki desain antarmuka yang interaktif dan mengandung unsur menyenangkan (Hurd dan Jenuings, dalam Wahono, 2009).

Menurut Randel (1991), game sangat berpotensi untuk menumbuhkan kembali motivasi belajar anak yang mengalami penurunan. Berdasarkan penelitian yang dilakukan oleh Randel pada tahun 1991 tercatat bahwa pemakaian 
game sangat bermanfaat pada materimateri yang berhubungan dengan matematika, fisika dan kemampuan berbahasa (seperti studi sosial, biologi dan logika).

Pada Seminar Nasional Teknologi Informasi dan Komunikasi Terapan 2011 (Semantik 2011) ISBN 979-26-02550,Sugiyanto dan Dzuha Hening Y mengangkat tema game edukasi "ragam budaya" sebagai media pembelajaran budaya tentang pakaian dan rumah adat di Indonesia. Dari penelitian pengembangan tersebut ditemukan hasil bahwa game dapat dijadikan sebagai alat bantu pembelajaran yang komunikatif dan menyenangkan bagi masyarakat baik anakanak maupun dewasa. Aplikasi game edukatif ini dapat dijadikan sebagai sarana hiburan sekaligus melestarikan warisan budaya di Indonesia.

Seiring jaman yang semakin berkembang dapat ditemukan bahwa game sekarang tampil dalam gadget yang lebih ringkas. Anak-anak bisa memainkan game di perangkat android atau tablet. Sering kita temui di keramaian bahwa anak-anak jaman sekarang sudah terbiasa dan terkesan cekatan menggunakan perangkat andriod, di mana yang biasanya mereka lakukan adalah bermain game di android. Harga android pun bisa dikatakan terjangkau sehingga hampir semua lapisan masyarakat memiliki android.

Dari keadaan di atas maka peneliti tertarik untuk mengembangkan education game berbasis android dengan judul " $M y$ Body" untuk Mata Pelajaran Bahasa Inggris Kelas II Sekolah Dasar. Dengan education game ini diharapkan siswa dapat belajar Bahasa Inggris dengan mudah dan menyenangkan sehingga penguasaan mereka terhadap materi menjadi lebih optimal. Hal ini dirasa masuk akal karena education game yang dikembangkan akan menampilkan visual dan audio sekaligus yang ditampilkan disesuaikan dengan karakteristik siswa.
Berdasarkan pemaparan latar belakang permasalahan di atas maka dapat dirumuskan masalah sebagai berikut:

Kondisi riil adalah media pembelajaran di sekolah masih memprihatinkan dan masih memerlukan pengembangan, baik jenis atau ragam dan kuantitasnya sesuai dengan tuntutan implementasi kurikulum. Media pembelajaran juga masih terbatas hanya berupa buku dan laboratorium saja. Hal tersebut tentu saja dirasakan masih kurang melihat jaman yang semakin maju dan perkembangan teknologi yang semakin pesat. Perlu adanya inovasi dalam dunia pendidikan agar pembelajaran dapat bermakna dan mengikuti perkembangan jaman.

Dari permasalahan tersebut maka kondisi ideal yang ingin dicapai adalah perlu dikembangkannya suatu media pembelajaran berupa education game yang dapat memberikan informasi yang jelas bagi peserta didik tentang mata pelajaran Bahasa Inggris tema anggota tubuh (my body), meningkatkan motivasi dan daya tarik peserta didik untuk belajar, serta media yang membelajarkan peserta didik di mana pun dan kapan pun mereka inginkan.

Berdasarkan permasalahan yang telah dipaparkan di atas maka tujuan penelitian pengembangan ini adalah untuk mengatasi permasalahan pembelajaran Bahasa Inggris dengan mengembangkan media pembelajaran berupa education gameberbasis android dengan judul " $M y$ Body" untuk Mata Pelajaran Bahasa Inggris Kelas II Sekolah Dasar yang menciptakan suasana belajar sambil bermain untuk memaksimalkan proses pembelajaran.

\section{Metode Pengembangan}

Jenis penelitian ini adalah
penelitian pengembangan karena
mengembangkan education game pada
mata pelajaran Bahasa Inggris tema "My


Body". Penelitian pengembangan ini dilaksanakan untuk menghasilkan suatu education game yang selanjutnya diujicobakan efektifitas, efisiensi, dan daya tarik dari education game tersebut.

Model pengembangan education game berbasis android pada mata pelajaran Bahasa Inggris tema "My Body" dapat menggunakan model Kemp dan Dayton, di mana langkah-langkah dalam pengembangan media pembelajaran education game harus melalui beberapa tahap, yaitu menentukan: (1) ide atau tujuan umum pembelajaran, (2) tujuan khusus pembelajaran, (3) karakteristik audiens, (4) isi materi (content outline), (5) treatment, (6) storyboard, (7) naskah (script), (8) developing, editing, and mixing, dan (9) testing and revising. Khusus pada tahap developing, editing, and mixing di atas pengembang menggunakan program komputer yaitu unity.

Pada dasarnya kegiatan uji coba produk pengembangan dilaksanakan sebagai langkah evaluasi formatif yang terdiri atas uji coba perorangan, uji coba kelompok kecil, dan uji coba kelompok besar (lapangan). Di mana sasaran uji coba di seluruh kegiatan uji coba tersebut adalah peserta didik Kelas II di SDN Socah 3 Bangkalan. Subjek uji coba adalah sasaran pengguna produk pengembangan yaitu peserta didik Kelas II SDN Socah 3 Bangkalan dengan jumlah 39 peserta didik. Dalam uji coba ini sasaran peserta didik yang dibutuhkan adalah 3 peserta didik untuk uji coba perorangan, 9 peserta didik untuk uji coba kelompok kecil, dan 27 peserta didik untuk uji kelompok besar (uji lapangan).

\section{Hasil Pengembangan dan Pembahasan}

Hasil penelitian pada pengembangan ini adalah berupa education gameyang berfungsi sebagai media dalam pembelajaran tema "My Body" untuk peserta didik Kelas II SD. Adapun hasil pengembangan yang menggunakan software unity ini dapat ditunjukkan dipaparkan dari gambar berikut ini:
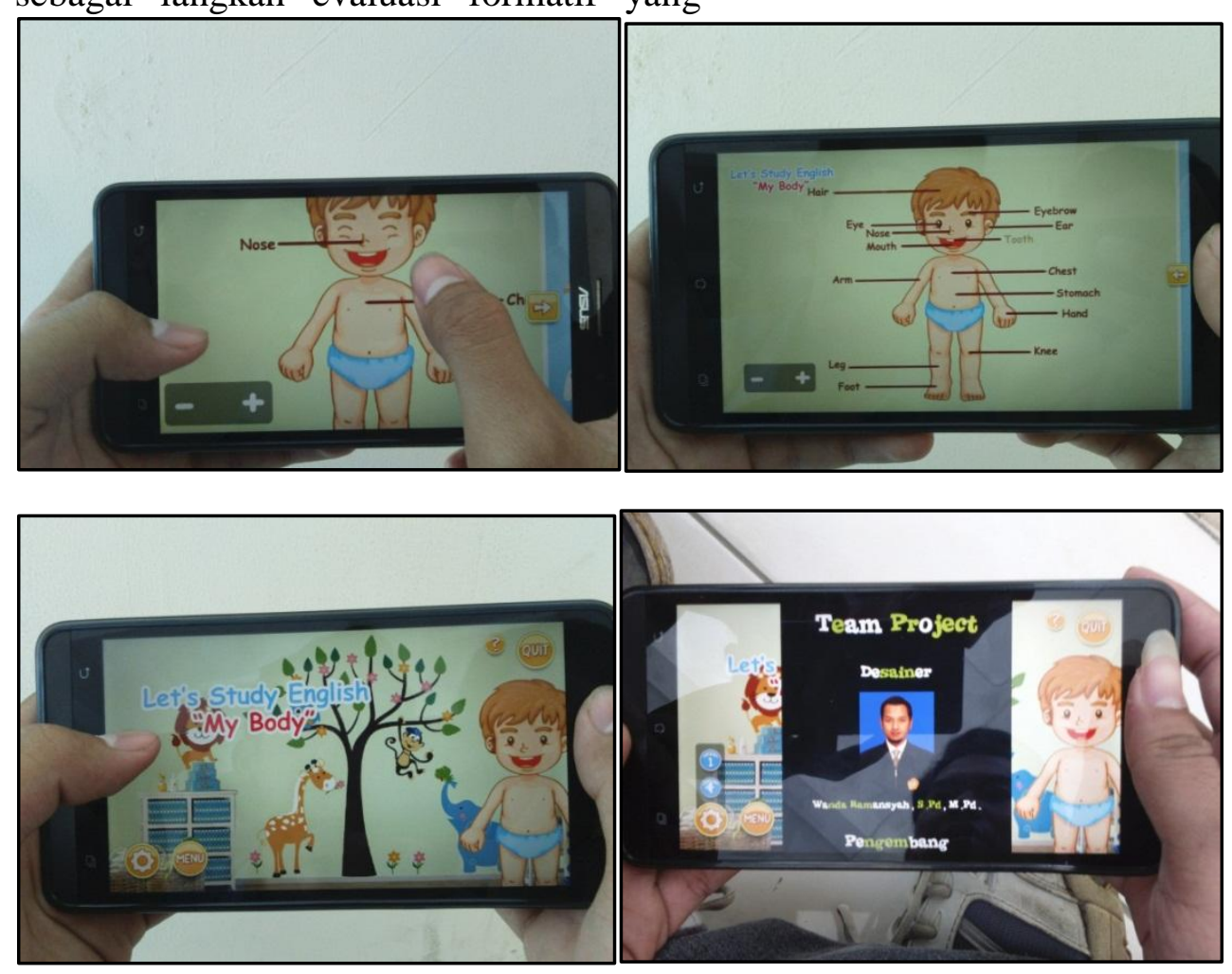


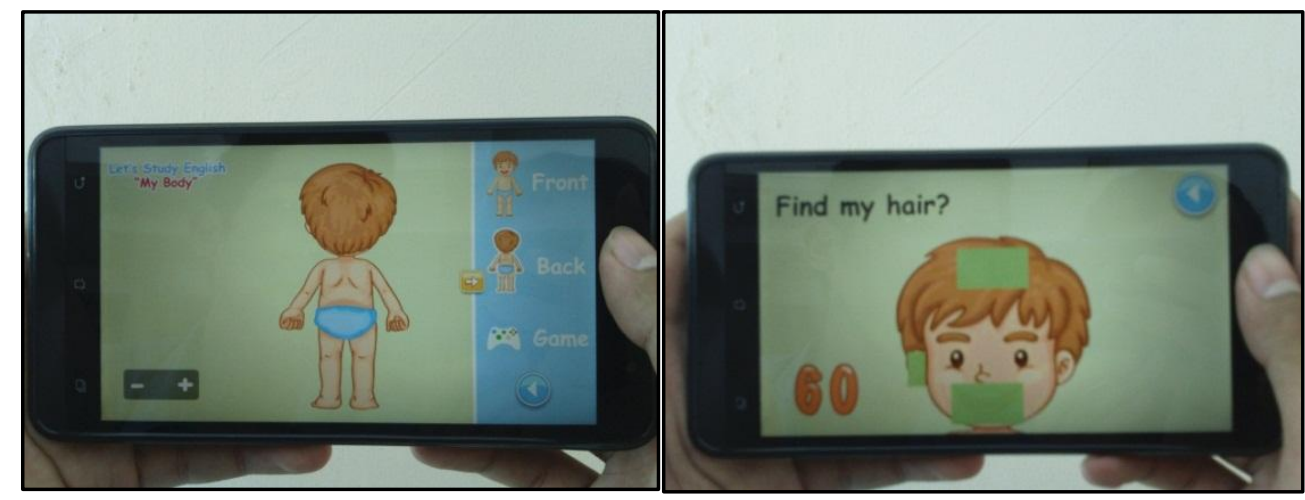

Gambar 1. Beberapa screenshot dalam education game

Dari pengembangan yang telah diciptakan maka dilakukan uji coba produk tersebut pada siswa Kelas II SDN Socah 3 Bangkalan untuk mengetahui efektifitas, efisiensi, dan daya tarik media. Dari uji coba produk baik secara perorangan, kelompok kecil, dan kelompok besar didapat data sebagai berikut:

Tabel 1. Komponen-Komponen yang Dinilai Pada Uji Coba Perorangan

\begin{tabular}{|c|c|c|c|c|c|}
\hline No. & Komponen yang dinilai & $\begin{array}{l}\text { Skor dari } \\
\text { responden }\end{array}$ & $\begin{array}{l}\text { Jumlah }\left(\sum\right) \\
\text { skor }\end{array}$ & $\begin{array}{l}\text { Rata-rata skor } \\
\text { ( } \sum \text { skor } / \\
\text { responden) }\end{array}$ & $\begin{array}{l}\text { Presentase } \\
\quad(\%)\end{array}$ \\
\hline 1. & $\begin{array}{l}\text { Kemampuan } \\
\text { education game dalam } \\
\text { menyampaikan materi-materi } \\
\text { pelajaran Bahasa Inggris. }\end{array}$ & 444 & 12 & 4 & $80 \%$ \\
\hline 2. & $\begin{array}{l}\text { Kejelasan isi materi-materi pada } \\
\text { education game }\end{array}$ & 444 & 12 & 4 & $80 \%$ \\
\hline 3. & $\begin{array}{l}\text { Kejelasan animasi pada } \\
\text { education game }\end{array}$ & 445 & 13 & 4,3 & $86 \%$ \\
\hline 4. & $\begin{array}{l}\text { Kejelasan teks pada education } \\
\text { game }\end{array}$ & 454 & 13 & 4,3 & $86 \%$ \\
\hline 5 . & $\begin{array}{l}\text { Kemampuan education } \\
\text { gameuntuk memudahkan siswa } \\
\text { dalam belajar }\end{array}$ & 554 & 14 & 4,7 & $93 \%$ \\
\hline 6. & $\begin{array}{l}\text { Kemudahan saat } \\
\text { mengoperasikan atau } \\
\text { menjalankan education game }\end{array}$ & 545 & 14 & 4,7 & $93 \%$ \\
\hline 7. & $\begin{array}{l}\text { Tampilan visual (gambar, video, } \\
\text { atau animasi) dalam } \\
\text { memudahkan siswa saat belajar }\end{array}$ & 444 & 12 & 4 & $80 \%$ \\
\hline 8. & $\begin{array}{l}\text { Daya tarik audio (musik, efek } \\
\text { suara, atau narasi) dalam } \\
\text { education game }\end{array}$ & 444 & 12 & 4 & $80 \%$ \\
\hline 9. & $\begin{array}{l}\text { Tampilan teks dan bentuk } \\
\text { tulisan (font) dalam education } \\
\text { game }\end{array}$ & 544 & 13 & 4,3 & $86 \%$ \\
\hline 10. & $\begin{array}{l}\text { Kombinasi, tatanan, dan } \\
\text { pemilihan warna dalam } \\
\text { education game }\end{array}$ & 455 & 14 & 4,7 & $93 \%$ \\
\hline \multicolumn{5}{|c|}{ Rata-rata prosentase keseluruhan } & $\mathbf{8 5 , 7 \%}$ \\
\hline
\end{tabular}


Tabel 2. Komponen-Komponen yang Dinilai pada Uji Coba Kelompok Kecil

\begin{tabular}{|c|c|c|c|c|c|}
\hline No. & Komponen yang dinilai & $\begin{array}{l}\text { Skor dari } \\
\text { responden }\end{array}$ & $\begin{array}{l}\text { Jumlah }\left(\sum\right) \\
\text { skor }\end{array}$ & $\begin{array}{c}\text { Rata-rata skor } \\
\left(\sum \text { skor/respond }\right. \\
\text { en })\end{array}$ & $\begin{array}{l}\text { Presentase } \\
(\%)\end{array}$ \\
\hline 1. & $\begin{array}{l}\text { Kemampuan } \\
\text { education game dalam } \\
\text { menyampaikan materi-materi } \\
\text { pelajaran Bahasa Inggris. }\end{array}$ & $\begin{array}{c}5455455 \\
55\end{array}$ & 43 & 4,7 & $94 \%$ \\
\hline 2. & $\begin{array}{l}\text { Kejelasan isi materi-materi pada } \\
\text { education game }\end{array}$ & $\begin{array}{l}5444445 \\
\quad 45 \\
\end{array}$ & 39 & 4,3 & $86 \%$ \\
\hline 3. & $\begin{array}{l}\text { Kejelasan animasi pada } \\
\text { education game }\end{array}$ & $\begin{array}{l}4445455 \\
\quad 45 \\
\end{array}$ & 40 & 4,4 & $88 \%$ \\
\hline 4. & $\begin{array}{l}\text { Kejelasan teks pada education } \\
\text { game }\end{array}$ & $\begin{array}{l}4444455 \\
\quad 45\end{array}$ & 39 & 4,3 & $86 \%$ \\
\hline 5. & $\begin{array}{l}\text { Kemampuan education } \\
\text { gameuntuk memudahkan siswa } \\
\text { dalam belajar }\end{array}$ & $\begin{array}{c}4444545 \\
\quad 45\end{array}$ & 39 & 4,3 & $86 \%$ \\
\hline 6. & $\begin{array}{l}\text { Kemudahan saat } \\
\text { mengoperasikan atau } \\
\text { menjalankan education game }\end{array}$ & $\begin{array}{l}4445545 \\
\quad 45\end{array}$ & 40 & 4,4 & $88 \%$ \\
\hline 7. & $\begin{array}{l}\text { Tampilan visual (gambar, video, } \\
\text { atau animasi) dalam } \\
\text { memudahkan siswa saat belajar }\end{array}$ & $\begin{array}{l}4444455 \\
\quad 45\end{array}$ & 39 & 4,3 & $86 \%$ \\
\hline 8. & $\begin{array}{l}\text { Daya tarik audio (musik, efek } \\
\text { suara, atau narasi) dalam } \\
\text { education game }\end{array}$ & $\begin{array}{l}4445455 \\
\quad 54\end{array}$ & 40 & 4,4 & $88 \%$ \\
\hline 9. & $\begin{array}{l}\text { Tampilan teks dan bentuk } \\
\text { tulisan (font) dalam education } \\
\text { game }\end{array}$ & $\begin{array}{l}4454455 \\
\quad 45\end{array}$ & 40 & 4,4 & $88 \%$ \\
\hline 10. & $\begin{array}{l}\text { Kombinasi, tatanan, dan } \\
\text { pemilihan warna dalam } \\
\text { education game }\end{array}$ & $\begin{array}{l}4555455 \\
55\end{array}$ & 43 & 4,7 & $94 \%$ \\
\hline \multicolumn{5}{|c|}{ Rata-rata prosentase keseluruhan } & $\mathbf{8 8 , 4} \%$ \\
\hline
\end{tabular}

Tabel 3. Komponen-Komponen yang Dinilai pada Uji Coba Kelompok Besar

\begin{tabular}{|c|c|c|c|c|c|}
\hline No. & Komponen yang dinilai & $\begin{array}{l}\text { Skor dari } \\
\text { responden }\end{array}$ & $\begin{array}{c}\text { Jumlah }\left(\sum\right) \\
\text { skor }\end{array}$ & \begin{tabular}{|} 
Rata-rata skor \\
$\left(\sum\right.$ skor/respond \\
en $)$
\end{tabular} & $\begin{array}{c}\text { Presentase } \\
(\%)\end{array}$ \\
\hline 1. & $\begin{array}{l}\text { Kemampuan } \\
\text { education game dalam } \\
\text { menyampaikan materi-materi } \\
\text { pelajaran Bahasa Inggris. }\end{array}$ & $\begin{array}{l}4445454 \\
5445554 \\
5455444 \\
455555\end{array}$ & 117 & 4,3 & $86 \%$ \\
\hline 2. & $\begin{array}{l}\text { Kejelasan isi materi-materi pada } \\
\text { education game }\end{array}$ & $\begin{array}{c}5445554 \\
5455444 \\
4445454 \\
455555\end{array}$ & 117 & 4,3 & $86 \%$ \\
\hline 3. & $\begin{array}{l}\text { Kejelasan animasi pada } \\
\text { education game }\end{array}$ & $\begin{array}{c}5454444 \\
4445454 \\
4545444 \\
445545\end{array}$ & 122 & 4,5 & $90 \%$ \\
\hline 4. & $\begin{array}{l}\text { Kejelasan teks pada education } \\
\text { game }\end{array}$ & $\begin{array}{l}4445454 \\
5454444 \\
4545444 \\
445545\end{array}$ & 122 & 4,5 & $90 \%$ \\
\hline
\end{tabular}




\begin{tabular}{|c|c|c|c|c|c|}
\hline 5. & $\begin{array}{l}\text { Kemampuan education } \\
\text { gameuntuk memudahkan siswa } \\
\text { dalam belajar }\end{array}$ & $\begin{array}{l}4445454 \\
4545444 \\
5454444 \\
445545 \\
\end{array}$ & 122 & 4,5 & $90 \%$ \\
\hline 6. & $\begin{array}{l}\text { Kemudahan saat } \\
\text { mengoperasikan atau } \\
\text { menjalankan education game }\end{array}$ & $\begin{array}{c}5454444 \\
4445454 \\
4545444 \\
445545\end{array}$ & 117 & 4,3 & $86 \%$ \\
\hline 7. & $\begin{array}{l}\text { Tampilan visual (gambar, video, } \\
\text { atau animasi) dalam } \\
\text { memudahkan siswa saat belajar }\end{array}$ & $\begin{array}{l}5545455 \\
5545555 \\
5544555 \\
455555\end{array}$ & 117 & 4,3 & $86 \%$ \\
\hline 8. & $\begin{array}{l}\text { Daya tarik audio (musik, efek } \\
\text { suara, atau narasi) dalam } \\
\text { education game }\end{array}$ & $\begin{array}{l}4545554 \\
4445454 \\
5455444 \\
455555\end{array}$ & 122 & 4,5 & $90 \%$ \\
\hline 9. & $\begin{array}{l}\text { Tampilan teks dan bentuk } \\
\text { tulisan (font) dalam education } \\
\text { game }\end{array}$ & $\begin{array}{c}4545554 \\
4445454 \\
5455444 \\
455555\end{array}$ & 117 & 4,3 & $86 \%$ \\
\hline 10. & $\begin{array}{l}\text { Kombinasi, tatanan, dan } \\
\text { pemilihan warna dalam } \\
\text { education game }\end{array}$ & $\begin{array}{c}4454454 \\
4545444 \\
5454444 \\
445545 \\
\end{array}$ & 117 & 4,3 & $86 \%$ \\
\hline \multicolumn{5}{|c|}{ Rata-rata prosentase keseluruhan } & $87,6 \%$ \\
\hline
\end{tabular}

Dari data yang dihasilkan saat uji coba perorangan yang terdiri dari tiga rata-rata prosentase secara keseluruhan mengenai kualitas education game pada tema "My Body" adalah 85,7\%. Hal ini menunjukkan bahwa produk education game berada pada kualifikasi "tinggi" atau "layak" dan tidak memerlukan revisi.

Dari data yang dihasilkan saat uji coba kelompok kecil yang terdiri dari sembilan peserta didik Kelas II SDN Socah 3 Bangkalan diketahui bahwa rata-rata prosentase secara keseluruhan mengenai kualitas education game pada tema "My Body" adalah $88,4 \%$. Hal ini menunjukkan bahwa produkeducation game berada pada kualifikasi "tinggi" atau "layak" dan tidak memerlukan revisi. peserta didik Kelas II SDN Socah 3 Bangkalan diketahui bahwa

Dari data yang dihasilkan saat uji coba kelompok besar yang terdiri dari dua puluh tujuh peserta didik Kelas II SDN Socah 3 Bangkalan diketahui bahwa ratarata prosentase secara keseluruhan mengenai kualitas education game pada tema "My Body" adalah 87,6\%. Hal ini menunjukkan bahwa produk education game pada berada pada kualifikasi "tinggi" atau "layak" dan tidak memerlukan revisi.

\section{Kesimpulan dan Saran}

Dari hasil penelitian yang telah dilakukan pengembang, maka education game pada tema "My Body" ini telah berhasil diuji tingkat efektifitas, efisiensi, dan daya tariknya. Di mana dari penelitian 
tersebut pengembang telah mendapatkan data yang mendukung bahwa produk yang dikembangkan telah memiliki nilai efektifitas, efisiensi, dan daya tarik untuk digunakan dalam pembelajaran. Hal ini terbukti dengan prosentase angket tanggapan atau penilaian peserta didik terhadap education game pada tema " $M y$ Body" yang berada pada angka $87,6 \%$ pada uji coba kelompok besar yang berarti berada dalam kualifikasi tinggi dan media layak digunakan tanpa direvisi.

Education game pada tema "My Body" ini menyajikan proses pembelajaran Bahasa Inggris sambil bermain dengan perangkat android. Produk pengembangan berupa education game pada tema " $M y$ Body" ini dapat digunakan sebagai sumber dalam meningkatkan strategi penyampaian pesan atau strategi mengajar guru agar lebih inovatif dan bermutu serta menyenangkan bagi siswa. Selain itu, instrumen-instrumen tambahan dalam multimedia (seperti: musik, gambar, animasi, dan efek suara) dapat menarik perhatian siswa dan menghilangkan kebosanan dalam belajar sehingga education game pada tema "My Body" ini dapat meningkatkan keinginan lebih siswa untuk belajar.

Saran pemanfaatan produk dari pengembang yang berkaitan dengan education game pada tema "My Body" ini adalah sebagai berikut:

a. Produk ini disarankan dalam kegiatan pembelajaran agar guru lebih kreatif dalam menyampaikan materi kepada siswa, menampilkan pembelajaran yang inovatif, tidak membosankan bagi siswa, dan lebih memudahkan siswa untuk memahami materi mata pelajaran Bahasa Inggrispada tema " $M y$ Body".

b. Produk education game pada tema "My Body"ini akan lebih baik manfaatnya jika guru dan siswa sudah tahu bagaimana mengoperasikan

education gameini.

c. Produk ini dapat digunakan sebagai media, alat, atau sarana dalam strategi penyampaian pesan pada proses pembelajaran dari seorang guru kepada siswanya yang membuat pembelajaran lebih bermakna dan menyenangkan bagi siswa.

d. Produk ini dalam pemanfaatannya harus didukung dengan tersedianya perangkat android yang beroperasi baik dan akan lebih baik dilengkapi dengan headset atau speaker.

\section{Daftar Pustaka}

Anwas, Oos M. 2003. Model Inovasi ELearning Dalam Meningkatkan Mutu Pendidikan.

Jurnal Teknodik: Edisi No.12/VII/Oktober/2003.

Degeng, I Nyoman, S. 1989. Teori Pembelajaran 1: Taksonomi Variabel. Malang: Universitas Negeri Malang.

Degeng, I Nyoman, S. 1990. Teori Pembelajaran 2: Terapan. Malang: Universitas Negeri Malang.

Degeng, I Nyoman, S. 1994. Teknologi Pembelajaran: Definisi dan Kawasannya Malang: Universitas Negeri Malang.

Hartanto, Antonius Aditya dan Onno W. Purbo. 2002. E-Learning berbasis PHP dan MySQL. Jakarta: Elex Media Komputindo.

Kemp, Jerrold E., dan Dayton, Deane K. 1985. Planning And Producing Instructional Media. New York: Harper \& Row Publisher Inc.

Ramansyah, Wanda. 2010. Pengembangan Multimedia Pembelajaran Interaktif Berbasis Komputer Pada Mata Diklat Dasar-Dasar Mesin. Tesis tidak diterbitkan. PPS Universitas Negeri Malang.

Richard A. Schwier dan Earl R. Misanchuk. (1993). Interactive 
Multimedia Instruction. New Jersey : Educational Technology Publications.

Rob Phillips. (1997). The Developer's Handbooks to Interactive Multimedia: A Practice Guide for Educational Applications. London: Kogan Page Limited.

Teknodik: Edisi No.12/VII/Oktober/2003. Seels, Barbara., dan Glasgow, Zita. 1998. Making Instructional Design Decisions. NewJersey: Prentice Hall Inc.

.Soekartawi. 2003. Prinsip Dasar ELearning: Teori Dan Aplikasinya
Sadiman, Arief, S. 2008. Media Pendidikan: Pengertian, Pengembangan, dan Pemanfaatannya. Jakarta: PT. Raja Grafindo Persada.

Saepudin, Asep. 2003. Penerapan Teknologi Informasi Dalam Pendidikan Masyarakat. Jurnal

Slavin, Robert E. 2008. Psikologi Pendidikan: Teori dan Praktek. Jakarta: PT. Indeks.

Smaldino, Sharon E. 2008. Instructional Technology and Media for Learning. New Jersey: Pearson Education

Ltd Di Indonesia. Jurnal Teknodik: Edisi No.12/VII/Oktober/2003 